\title{
IDENTIFYING R\&D SUCCESS PARTNERSHIP FOR NEPALESE UNIVERSITIES USING ANALYTIC HIERARCHY PROCESS
}

\begin{abstract}
Nepalese universities have been practicing collaborative activities in the recent time with multiple agencies ranging from industries to universities both at national and international level. The current focus of the institutions seems to be only on maximizing the number of collaboration rather than focusing on the core competency. Because of this, institutions are found to be diverting from their core values, the institutional growth in the key area is stagnant, and the research activities conducted at the institutions are not producing tangible results. Experts from the research and development units of the institutions believe that there should be proper strategic path regarding partnership selection. While developing strategy, there is a need of consideration of multiple factors associated with excellence in several key areas along with multiple alternatives. AHP has been used in this research to identify best alternative for partnership along with most important factor.
\end{abstract}

Keywords: research and development, universities, partnership.

\section{Introduction}

Nepalese universities have been practicing various forms of collaborative activities for a long time. The type of collaboration depends on the institution and its capability of influencing partners. Institutions are found to be grasping every type of collaboration that comes in their way without identifying their core competency and sustainable benefit that may result from the partnership. Due to this, the institutions are overburden with the partnership projects but the vision and mission seem to be missing and the organizations are diverting from their strategic path. Furthermore, the projects terminate without any significant achievement and the partner agencies are reluctant for additional collaboration. In addition, the opportunity cost of the institutions is high, as the selection of projects seems to be difficult.

\section{Rationality of the study}

The institutions management is facing the problem of over or under utilization of resources and the growth of the organizations in the core area is stagnant. Several partnership options are available and the management is unable to prioritize which option would be most beneficial among the pool of options.

\section{Research question}

Which is the most successful R\&D partnership option for Nepalese universities and colleges?

\section{Literature Review}

University and industry collaboration is perceived as a vehicle to enhance innovation through knowledge exchange (Ankrah, 2015). Many industries outsource their R\&D activities to universities and remain competitive. This partnership represent a valuable source of funding for university research (Mirabent, 2015). Further, Heitor M. (2015) highlighted the successful universities partnership with industry and the government. AHP is capable of breaking complex problems into smaller parts that can be easily handled by human intelligence (Saaty, 2008)

\section{Objectives}

To develop a model that could guide university authorities to develop a policy regarding R\&D partnership selection in Nepal. 


\section{Research Design}

AHP model has been developed based on the literatures and interview with R\&D project managers at Nepalese universities. Thirty respondents have been chosen who were directly involved with $\mathrm{R}$ and $\mathrm{D}$ projects in a capacity of Principle investigator or Project evaluator. Data collection has been done on individual basis with the use of pair wise comparison questionnaire. Geometric mean of the valid data collected from individual respondents has been calculated to aggregation.

\section{Model Analysis}

The developed model has five levels. Goal is at level one followed by four factors that are important to be considered in selection of partnership at level two. Subfactors (SFs) at level three and Sub-sub factors (SSFs) at level four. In addition, the four partnership alternatives are placed at level five as shown in the figure below.

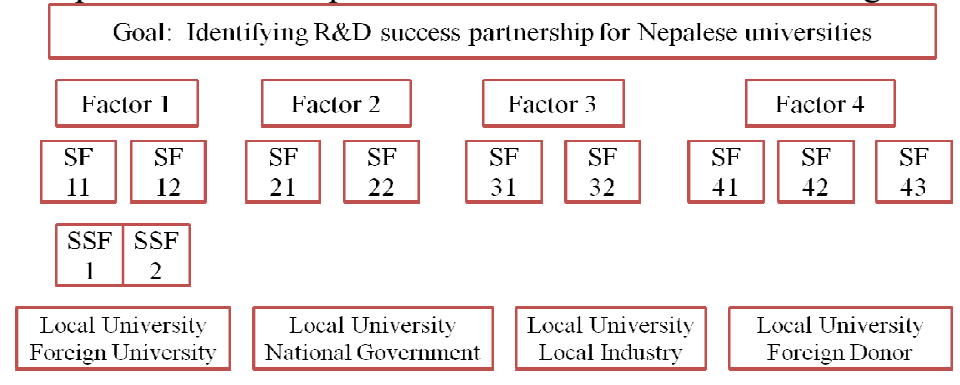

\section{Limitations}

The method relies on subjective judgments for the analysis. The weights that are assigned to the decision makers can be tilted in favor such that the result will reflect the opinion of a selected few people. Maintaining consistency is also a very critical factor for the members' views to be accurately reflected in the results. Within a small group, an inconsistent input from a single member can immediately have an effect on the overall rankings.

\section{Conclusions}

This study is probably the first ever study done at Nepalese educational institutions regarding R\&D partnership selection from the perspective of MCDM. This could be a good model for strategic planning committee to develop R\&D policy for the universities to achieve competitive advantage.

\section{Key References}

Ankrah, S. (2015), Universities - industry collaboration: A systematic review, Scandinavian Journal of Management, 31(3), 387-408

Mirabent, J. B. et al., University-industry partnerships for the provision of R\&D services, Journal of Business Research, 68(7), 407-1413

Heitor, M. (2015), How university global partnerships may facilitate a new era of international affairs and foster political and economic relations, Technological Forecasting \& Social Change, 95, 276-293

Saaty, T. L. (2008), Decision making with the analytic hierarchy process, Int. J. Services Sciences, 1(1), 83-98. 